\title{
Analisis Kualitatif Formalin pada Ikan Asin di Pasar Jodoh Kota Batam
}

\section{Qualitative Analysis of Formalin in Salted Fish in Pasar Jodoh Kota Batam}

\author{
Hesti Marliza, Suhaera*, Trinur Atika Saputri \\ Prodi Sarjana Farmasi, Stikes Mitra Bunda Persada, Jalan Seraya No. 1 Teluk Tering, Kota \\ Batam, Kepulauan Riau 29441, Indonesia \\ *Corresponding author email: esuhaera@gmail.com
}

Received 10-10-2019 Accepted 30-11-2019 Available online 30-12-2019

\begin{abstract}
ABSTRAK
Ikan asin merupakan produksi bahan ikan segar yang ditambahkan garam sekitar 1520\%. Cara tradisional ini memiliki kekurangan seperti terkendala saat musim penghujan sehingga proses penjemuran ikan asin menjadi tidak sempurna yang mengakibatkan ikan asin cepat mengalami kerusakan, karena itu banyak pedagang ikan asin menggunakan bahan kimia berbahaya seperti formalin untuk mengawetkan ikan asin agar bertahan lama dan tidak membusuk. Penelitian ini bertujuan untuk mendeteksi adanya kandungan formalin pada ikan asin yang dijual di Pasar Jodoh, Kota Batam. Metode yang digunakan adalah analisis kualitatif. Hasil dari pengujian 18 sampel ikan asin yang diambil dari Pasar Jodoh, Kota Batam, negatif mengandung formalin.
\end{abstract}

Kata kunci: analisis kualitatif, formalin, ikan asin.

\section{ABSTRACT}

Salted fish is a product made from fresh fish with the addition of 15-20\% salt. In the rainy season, the drying of salted fish by the traditional method is hindered and might result in the possibility of spoilage of the fish. Some merchants might use chemicals, such as formalin, to prevent salted fish from spoilage. This study aims to detect the presence of formaldehyde in salted fish sold in Jodoh Market, Kota Batam. The method used is qualitative analysis. The results showed that all 18 salted fish were negatively containing formalin.

Key words: qualitative analysis, formalin, salted fish. 


\section{Pendahuluan}

Wilayah Indonesia secara geografis merupakan negara kepulauan terbesar di dunia terutama untuk sektor perikanan. Berdasarkan data Badan Pusat Statistik dan Departemen Kelautan dan Perikanan Jakarta, produksi ikan di Indonesia hingga tahun 2007 masih didominasi sektor penangkapan yang mencapai $61,53 \%$ dari total produksi. Ikan termasuk jenis bahan pangan yang mudah rusak (membusuk). Cara agar ikan tetap awet yaitu dengan pengawetan secara tradisional dengan penggaraman. Ikan asin merupakan produksi dari bahan ikan segar atau ikan setengah basah yang ditambah garam sekitar $15-20 \%$. Langkah-langkah dalam proses pembuatan ikan asin yaitu, penyiangan, pencucian, penggaraman, pengeringan, dan pengepakan. Cara tradisional ini sendiri memiliki kekurangan saat proses pengawetan seperti terkendala pada saat musim penghujan. Ikan yang diproduksi akan mengalami pengeringan yang tidak sempurna dan berair. Proses penggaraman memakan waktu yang lama (12-14 hari) dan ikan asin akan cepat mengalami kerusakan pada suhu di atas $15{ }^{\circ} \mathrm{C}$. Karena itu banyak pedagang menggunakan formalin agar ikan asin menjadi lebih awet (Sari, 2011).

Penggunaan formalin pada bahan makanan yaitu untuk mengawetkan produk agar tahan lama serta penggunaannya yang mudah. Murahnya harga formalin menjadi faktor yang membuat produsen dan pedagang menggunakannya sebagai bahan tambahan makanan untuk meraih keuntungan yang lebih besar, serta didukung oleh perilaku konsumen yang memilih produk yang awet dan tahan lama dengan harga murah (Adawyah, 2011).

$\begin{array}{lr}\text { Menurut Peraturan } & \begin{array}{r}\text { Menteri } \\ \text { Nomor }\end{array} \\ \text { 1168/MenKes/PER/X/1999 } & \text { tentang } \\ \text { Bahan Tambahan Makanan, } & \text { formalin }\end{array}$
merupakan bahan kimia yang penggunaannya dilarang untuk produk makanan. Formalin ini biasanya digunakan sebagai bahan baku industri, serta larutan dari formaldehida ini sering dipakai membunuh bakteri serta mengawetkan bangkai, dan lain-lainnya. Penggunaan formalin pada makanan tidak diperbolehkan karena dapat menyebabkan keracunan pada tubuh manusia. Gejala keracunan formalin yang dapat dilihat antara lain adalah mual, sakit perut yang akut disertai muntah-muntah, diare berdarah, timbulnya depresi susunan syaraf dan gangguan peredaran darah, dan dapat menyebabkan kematian.

Adanya pemberitaan Badan Pengawasan Obat dan Makanan (BPOM) di Kepulauan Riau mengidentifikasi kandungan zat berbahaya seperti borak dan formalin pada bahan makanan di sejumlah titik Kota Batam. Beberapa penelitian di Kecamatan Tampan, Pekanbaru dinyatakan 2 sampel positif mengandung formalin dari 10 sampel ikan asin (Antoni, 2010). Hasil penelitian di Malang, dari 5 sampel, 3 sampel ikan asin positif mengandung formalin (Singgih, 2013). Penelitian di Pasar km 5 
Palembang, dari 17 sampel, 8 sampel ikan asin positif mengandung formalin (Mersita, 2016).

Berdasarkan permasalahan tersebut, dilakukan penelitian tentang ada atau tidaknya kandungan formalin pada ikan asin yang dijual di Pasar Jodoh, yaitu dengan analisis kualitatif dengan pereaksi $\mathrm{KMnO}_{4}$ 0,1 N, Fehling $\mathrm{A}$ dan fehling B, Nash, dan Tollens.

\section{Metode Penelitian}

\section{Alat dan Bahan}

Alat-alat yang digunakan dalam penelitian ini adalah spektrofotometer UV-Visibel (Shimadzu UV 1800), timbangan analitik (Kenko), pipet tetes, penangas air, tabung reaksi, gelas ukur, batang pengaduk, labu ukur, mortir, spatel, dan kaca arloji. Sedangkan bahan-bahan yang digunakan dalam penelitian ini adalah 18 sampel ikan asin, akuades, $\mathrm{KMnO}_{4}$ 0,1 N, Fehling A, Fehling B, pereaksi Nash, dan pereaksi Tollens.

\section{Jalannya Penelitian}

1. Pengambilan sampel

Pengambilan sampel ikan asin dilakukan dengan cara purposive sampling di Pasar Jodoh, Kota Batam. Sampel yang diambil, berjumlah 1 sampel dari pedagang yang berbedabeda sehingga diperoleh total sampel sebanyak 18 sampel ikan asin yang diberi kode A sampai $R$.

2. Uji kualitatif formalin pada ikan asin
a. Pembuatan kontrol positif dan kontrol negatif
Pembuatan kontrol positif menggunakan 1 ekor ikan asin

yang direndam dengan larutan formalin. Sedangkan kontrol negatifnya dengan cara pembuatan ikan segar menjadi ikan asin, diambil 1 ekor ikan segar berdaging tebal setelah itu ikan dibersihkan lalu ditambahkan garam dan didiamkan selama 24 jam. Ikan kemudian dikeringkan dengan cara dijemur.

b. Pembuatan pereaksi $\mathrm{KMnO}_{4}, 0,1 \mathrm{~N}$ Sebanyak $0,3160 \mathrm{~g} \quad \mathrm{KMnO}_{4}$. Dilarutkan dengan akuades di labu ukur $100 \mathrm{ml}$. Larutan $\mathrm{KMnO}_{4}$ kemudian dipanaskan selama 15 menit, didinginkan pada suhu kamar. Larutan ini disimpan dalam botol yang gelap.

c. Uji kualitatif formalin dengan larutan $\mathrm{KMnO}_{4} 0,1 \mathrm{~N}$

Sampel ikan asin ditimbang 10 gram, digerus menggunakan lumpang hingga halus, ditambahkan $30 \mathrm{ml}$ akuades, disaring menggunakan kertas saring, dan diambil filtratnya. Sebanyak $1 \mathrm{ml}$ filtrat, dimasukkan ke dalam tabung reaksi dan ditambahkan larutan $\mathrm{KMnO}_{4}$ 0,1 N sebanyak 3 tetes. Jika warna ungu tua menghilang kemudian menjadi pudar (bening) dalam waktu 30 menit maka sampel ikan asin positif mengandung formalin. Uji pembanding dilakukan berupa kontrol positif dan kontrol negatifnya (Hastuti, 2010).

d. Uji kualitatif formalin dengan Fehling A dan Fehling B 
Larutan Fehling A dan Fehling B dicampurkan dengan volume sama banyak, yaitu $1 \mathrm{ml}$ Fehling A dicampurkan dengan $1 \mathrm{ml}$ Fehling B. Selanjutnya hasil filtrat $(1 \mathrm{ml})$ dimasukkan ke dalam tabung reaksi, ditambahkan pereaksi Fehling A dan Fehling B dengan volume yang sama yaitu sebanyak $1 \mathrm{ml}$, kemudian dimasukkan dalam penangas air yang selanjutnya dipanaskan. Selama proses pemanasan, diamati perubahan yang terjadi. Apabila terjadi perubahan yaitu terdapat endapan merah bata, maka sampel yang diuji positif mengandung formalin (Hastuti, 2010).

3. Uji kualitatif formalin dengan pereaksi Nash

Pereaksi Nash dibuat dari 15 gram ammonium asetat $\left(\mathrm{NH}_{4} \mathrm{CH}_{3} \mathrm{COO}\right)$ ditambahkan $0,3 \mathrm{ml}$ asam asetat $\left(\mathrm{CH}_{3} \mathrm{COOH}\right)$, dan $0,2 \mathrm{ml}$ asetil aseton, lalu diencerkan dengan akuades 100 ml (Hendrik, 2010). Sebanyak $1 \mathrm{ml}$ filtrat ikan asin dimasukkan ke dalam tabung reaksi kemudian ditambahkan $1 \mathrm{ml}$ pereaksi Tollens lalu digojok. Setelah itu larutan dipanaskan sampai timbul gelembung, perubahan yang terjadi jika positif formalin warna berubah menjadi hitam dan terbentuk cermin perak di permukaan. Pereaksi Nash dipipet sebanyak $3 \mathrm{ml}$ kemudian dimasukkan ke dalam tabung reaksi, filtrat ikan asin sebanyak $3 \mathrm{ml}$ dicampurkan ke dalam tabung reaksi dalam keadaan tertutup, dipanaskan selama 30 menit pada suhu $40{ }^{\circ} \mathrm{C}$ lalu dibiarkan dingin selama 30 menit. Jika positif formalin, menghasikan warna kuning yang stabil (Hendrik, 2010).

4. Uji kualitatif formalin dengan pereaksi Tollens

Perak nitrat $100 \mathrm{ml}$ dilarutkan dalam akuades, ditambahkan $5 \mathrm{ml}$ larutan $\mathrm{NaOH} 5 \%$, setelah itu ditambahkan $7,5 \mathrm{ml}$ ammonia pekat, didapat perak ammonia nitrat (pereaksi tollens). Uji kualitatif formalin dengan pereaksi Tollens adalah sebagai berikut: sebanyak $1 \mathrm{ml}$ filtrat ikan asin dimasukkan ke dalam tabung reaksi kemudian ditambahkan $1 \mathrm{ml}$ pereaksi Tollens, lalu digojok. Larutan dipanaskan sampai timbul gelembung, perubahan yang terjadi jika positif formalin warna berubah menjadi hitam dan terbentuk cermin perak di permukaan.

5. Analisis data

Penelitian ini merupakan
penelitian deskriptif. Hasilnyang
diperoleh dibuat dalam bentuk tabel
dan gambar.

\section{Hasil dan Pembahasan}

Pada penelitian ini dilakukan pengambilan sampel ikan asin dilakukan dengan cara purposive sampling di Pasar Jodoh, Kota Batam. Penelitian ini dilaksanakan pada bulan Maret-Juni 2019, di Laboratorium Kimia Farmasi Analisis, Program Studi Sarjana Farmasi, Sekolah Tinggi Ilmu Kesehatan Mitra Bunda Persada Batam. Hasil uji analisis kandungan formalin dapat dilihat pada Tabel 1. 
Vol.16 No. 02 Desember 2019:307-314

Tabel 1. Hasil uji kualitatif formalin pada 18 sampel ikan asin

\begin{tabular}{cccccc}
\hline \multirow{2}{*}{$\begin{array}{c}\text { Sampel } \\
\text { Ikan Asin }\end{array}$} & \multicolumn{4}{c}{ Uji Kualitatif } \\
\cline { 2 - 6 } & KMnO $\mathbf{0 , 1}$ N & Fehling A dan Fehling B & Nash & Tollens & Hasil \\
\hline A & Kecoklatan & Tidak ada endapan & Bening & Coklat & Negatif \\
B & Kecoklatan & Tidak ada endapan & Bening & Coklat & Negatif \\
C & Kecoklatan & Tidak ada endapan & Bening & Coklat & Negatif \\
D & Kecoklatan & Tidak ada endapan & Bening & Coklat & Negatif \\
E & Kecoklatan & Tidak ada endapan & Bening & Coklat & Negatif \\
F & Kecoklatan & Tidak ada endapan & Bening & Coklat & Negatif \\
G & Kecoklatan & Tidak ada endapan & Bening & Coklat & Negatif \\
H & Kecoklatan & Tidak ada endapan & Bening & Coklat & Negatif \\
I & Kecoklatan & Tidak ada endapan & Bening & Coklat & Negatif \\
J & Kecoklatan & Tidak ada endapan & Bening & Coklat & Negatif \\
K & Kecoklatan & Tidak ada endapan & Bening & Coklat & Negatif \\
L & Kecoklatan & Tidak ada endapan & Bening & Coklat & Negatif \\
M & Kecoklatan & Tidak ada endapan & Bening & Coklat & Negatif \\
N & Kecoklatan & Tidak ada endapan & Bening & Coklat & Negatif \\
O & Kecoklatan & Tidak ada endapan & Bening & Coklat & Negatif \\
P & Kecoklatan & Tidak ada endapan & Bening & Coklat & Negatif \\
Q & Kecoklatan & Tidak ada endapan & Bening & Coklat & Negatif \\
R & Kecoklatan & Tidak ada endapan & Bening & Coklat & Negatif \\
\hline
\end{tabular}

Pada Tabel 1 didapatkan hasil 18 sampel ikan asin tidak mengandung formalin. Penelitian ini bertujuan untuk mengetahui ada atau tidaknya kandungan formalin pada ikan asin yang dijual di Pasar Jodoh, Kota Batam. Pemilihan sampel yang diambil berdasarkan ciri-ciri ikan asin yang teksturnya tidak lembek, bersih, dan tidak dihinggapi lalat. Adapun sampel ikan asin yang diambil yaitu ikan asin yang berdaging tebal, karena ikan asin berdaging tebal mudah membusuk dan cepat berair, jika dalam penjemuran ikan asin tidak kering seperti ikan asin peda atau kembung, ikan asin gabus, ikan asin katamba, ikan asin manyung, dan ikan asin kerapu. Sebanyak 18 sampel diambil secara acak. Setelah itu dilakukan pemeriksaan ada atau tidaknya kandungan formalin pada sampel ikan asin.

Pada 18 sampel ikan asin yang di uji, didapatkan hasil perubahan warna dari ungu tua menjadi kecoklatan dalam durasi waktu satu jam, hal ini menandakan sampel negatif mengandung formalin. Perubahan warna pada larutan $\mathrm{KMnO}_{4}$ 0,1 $\mathrm{N}$ disebabkan karena aldehida mereduksi $\mathrm{KMnO}_{4}$ menjadi asam karboksilat (Persamaan reaksi 1) sehingga warna larutan yang awalnya ungu tua menjadi putih bening (Rahmadani, 2008).

$$
\begin{array}{r}
5 \mathrm{R}-\mathrm{CHO}+\mathrm{KMnO}_{4} \\
\text { (ungu) }
\end{array} \rightarrow 5 \mathrm{R}-\mathrm{COOH}+\mathrm{MnO}_{2}
$$


Pengujian dengan Fehling $A$ dan Fehling B didapatkan hasil 18 sampel tidak mengandung formalin karena tidak adanya endapan merah bata saat pemanasan selama 2-3 menit. Pemanasan dilakukan karena pereaksi Fehling kurang stabil pada larutan dingin, sehingga butuh pemanasan. Pada kontrol positifnya, pereaksi Fehling A dan Fehling B ditambahkan dengan sampel ikan asin yang sudah diberikan formalin, akan membentuk endapan merah bata saat dipanaskan di penangas air selama 2-3 menit. Hal ini disebabkan karena senyawa aldehida dioksidasi menjadi asam karboksilat dan terbentuk endapan $\mathrm{Cu}_{2} \mathrm{O}$ seperti ditunjukkan pada Persamaan 2 (Manoppo et al., 2014).

$$
\begin{aligned}
& \mathrm{R}-\mathrm{CHO}+\mathrm{Cu}^{2+} \rightarrow \mathrm{R}-\mathrm{COO}+\mathrm{Cu}_{2} \mathrm{O} \\
& \text { (Biru) (Merah Bata) }
\end{aligned}
$$

Pada uji penegasan warna kuning stabil setelah dipanaskan menggunakan pereaksi Nash dan di atas penangas air dengan suhu $40{ }^{\circ} \mathrm{C}$. Tollens, 18 sampel ikan asin direaksikan Hal ini disebabkan adanya reaksi dengan pereaksi Nash didapatkan hasil formalin dengan asam asetil aseton dan negatif mengandung formalin yang ammonia membentuk diacetyl-dihydroditandai dengan perubahan warna lutidine (DDL) yang membentuk warna bening. Pada kontrol positifnya, bereaksi kuning stabil (Rahman, 2014). dengan formalin akan membentuk

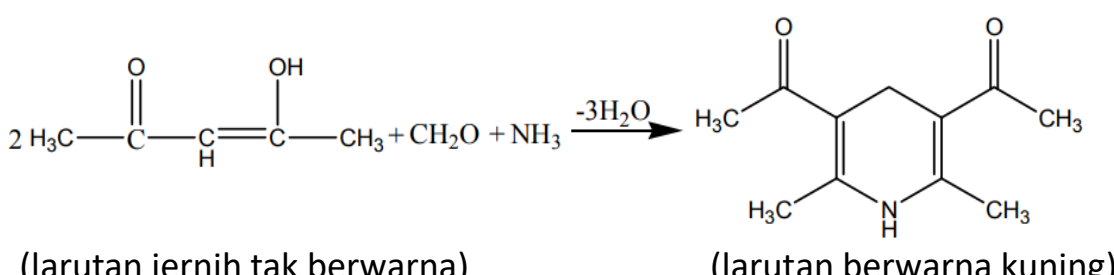

Gambar 1. Reaksi formalin dengan pereaksi Nash (Saptarini et al., 2011).

Pada pereaksi Tollens, sebagai uji akhir dari 18 sampel ikan asin, didapatkan hasil negatif yang ditandai dengan warna coklat setelah pemanasan serta tidak adanya endapan cermin perak. Pada kontrol positifnya membentuk cermin perak atau endapan perak (Persamaan 3), dikarenakan formalin bersifat reduktor sehingga dapat merubah larutan menjadi perak metalik asam karboksilat dan terbentuk endapan (Marliana, 2008). 


$$
\begin{aligned}
\mathrm{R}-\mathrm{CHO}+2 \mathrm{Ag}\left(\mathrm{NH}_{3}\right)_{2} \mathrm{OH}_{2} \rightarrow & \mathrm{Ag}+\mathrm{R}-\mathrm{COOH}-\mathrm{NH}_{4}^{+}+3 \mathrm{NH}_{3}+\mathrm{H} 2 \mathrm{O} \\
& \text { (Cermin perak) }
\end{aligned}
$$

\section{Simpulan}

Hasil dari penelitian analisis kandungan formalin pada ikan asin yaitu didapatkan hasil negatif pada 18 sampel ikan asin dan dapat disimpulkan bahwa ikan asin yang dijual di Pasar Jodoh, Kota Batam tidak terdeteksi adanya formalin. Penelitian ini tidak dilanjutkan uji kuantitatif dengan spektrofotometri UVVisibel dikarenakan sampel ikan asin negatif tidak terdeteksi adanya formalin.

\section{Daftar Pustaka}

Antoni, S. 2010, Analisa kandungan formalin pada ikan asin dengan metode spektrofotometri di Kecamatan Tampan Pekanbaru. Skripsi. Fakultas Tarbiyah dan Keguruan, Universitas Islam Negeri Sultan Syarif Kasim.

Adawyah, R. 2011. Pengolahan dan Pengawetan Ikan. Jakarta: Bumi Aksara.

Hastuti, S. 2010. Analisis kualitatif dan kuantitatif formaldehid pada ikan asin di Madura. Agrointek, 4(2):132-137.

Singgih, H. 2013. Uji kandungan formalin pada ikan asin menggunakan sensor warna dengan bantuan FMR. Jurnal Eltek, 2(1):55-70.

Hendrik. 2010. Analisis usaha pengolahan ikan asin di Kecamatan Pandan Kabupaten Tapanuli Tengah Sumatera
Utara. Jurnal Perikanan dan Kelautan, 15(1):83-88.

Mersita, R. 2016. Uji kandungan formalin pada ikan asin di pasar $\mathrm{km} 5$ Palembang. Jurnal Bioilmi, 2(2):121-128.

Manoppo, G., Abidjulu, J., Wehantouw, F. 2014. Analisis formalin pada buah impor di Kota Manado. Pharmacon Jurnal Ilmiah Farmasi, 3(3):148-155.

Marliana, H. 2008. Optimasi pereaksi Schryver menjadi kertas indikator untuk identifikasi formalin dalam sampel makanan. Skripsi. FMIPA, Universitas Indonesia, Depok.

Rahman, T.K. 2014. Analisis kadar formalin pada ikan asin yang dipasarkan di Kota Gorontalo. Tesis. Universitas Negeri Gorontalo.

Rahman, T. 2014. Analisa kadar formalin pada ikan asin yang dipasarkan di Kota Gorontalo. Tesis. Universitas Negeri Gorontalo.

Rahmadani, E.F. 2008. Deteksi daging ayam yang diformalin secara visual, organoleptik, kimia dan fisika. Skripsi. Departemen Teknologi Pertanian, Fakultas Pertanian, Sumatra Utara.

Sari, M.K. 2011. Analisis usaha pengolahan ikan asin di Kabupaten Cilacap. Skripsi. 
Fakultas Pertanian, Universitas Sebelas Maret.

Saptarini, Wardati, Supriatna. 2011. Deteksi formalin dalam tahu di
Pasar Tradisional Purwakarta. Jurnal Penelitian Sains \& Teknologi, 12(1):37-44. 